\title{
A CROSS-SECTIONAL STUDY OF THE IMPACT OF STANDARDISED TOBACCO PACKAGING LEGISLATION ON UNIVERSITY STUDENTS
}

Background: European Union and national legislation implemented from May 2016 mean that from May 2017 all tobacco products in the UK must be sold in standardised packs without external branding and with prominent graphic health warnings. This study investigates the level of awareness and acceptability of the legislation in students during the implementation period, and how the legislation may impact on student perceptions of pack attributes, health warning effectiveness, student smokers' willingness to pay for cigarette packs and intentions to quit.

Methods: An online survey link was emailed to randomly selected University of Nottingham students in autumn 2016. Descriptive statistics and multivariate logistic regression models were used to investigate awareness, acceptability and potential quitting behaviour.

Results: 546 students (175 smokers, 371 non-smokers) responded. 11.7\% of students had seen a standardised pack. Smokers were more likely to be aware of the new legislation than non-smokers (OR 2.15 CI 1.41-3.27). More smokers noticed the warnings on standardised packs than on branded ones $(98.8 \%$ vs. $78.9 \%$, p <0.001). Fewer smokers were willing to pay current prices for standardised packs than for branded packs ( $72 \%$ vs. $100 \%, \mathrm{p}<0.001)$. $46.2 \%$ of smokers anticipated quitting in response to the new legislation, with those who smoke infrequently being more likely to anticipate quitting than daily smokers.

Conclusions: Few students had seen a standardised pack, suggesting that the level of implementation of the legislation was low 5-6 months into the implementation period. However, the findings suggest that the legislation has the potential to increase quitting behaviour in smoking students. 
Impact of standardised tobacco packs on students

\section{Introduction}

Historically, tobacco packaging has been designed to promote brand names, change perceptions of product risk and quality, distract attention away from health warnings, and, in particular, appeal to young people - the next generation of smokers.(Borland, Savvas, Sharkie, \& Moore, 2013; Ford, Moodie, MacKintosh, \& Hastings, 2013; Ford, MacKintosh, Moodie, Richardson, \& Hastings, 2013; Ford, Moodie, Mackintosh, \& Hastings, 2013; Gendall et al., 2011; Hammond et al., 2009; Hammond \& Parkinson, 2009; Maynard, Munafo, \& Leonards, 2013; Moodie et al., 2013; Moodie et al., 2012; Scheffels \& Saebo, 2013) Until recently, following bans on tobacco advertising, tobacco direct marketing and tobacco company sponsorship, tobacco packaging remained as one of the few means for tobacco companies to promote smoking in the UK.

From May 2016 new tobacco standardised (unbranded) packaging legislation was implemented in the UK with a view to reducing the appeal of tobacco products to consumers, particularly young people.(DH, 2016) The new European Union Tobacco Products Directive introduced changes to tobacco packaging including increased graphic health warnings covering $65 \%$ of the front and back of these packs, minimum pack sizes of 20 cigarettes or $30 \mathrm{~g}$ of loose tobacco, and the prohibition of novel pack shapes.(Directive 2014/40/EU, 2014) National legislation implemented in parallel with the EU legislation saw the UK become the second country in the world (after Australia in 2012) to implement standardised tobacco packaging. Standardised packaging legislation requires packs to be free from all imagery and branding with the exception of the product and variant name in standard sized Helvetica font.(The Standardised Packaging of Tobacco Products Regulations 2015, 2015) The only colour permitted on the external packaging is pantone 448C, a drab dark brown colour. A one year implementation period until $20^{\text {th }}$ May 2017 was permitted for the sale of the remaining stock of packs which did not comply with the new legislation.

Evidence from Australia suggests that standardised packaging increased quit attempts in adult smokers and reduced smoking prevalence.(Diethelm \& Farley, 2015; Durkin et al., 2015) However, the timing of any changes in behaviour related to standardised packaging is dependent on the time at which the packs actually appear in shops and become the norm. Evidence on the speed of implementation in the UK is currently lacking. Furthermore, the majority of the existing evidence on standardised packaging precedes the implementation of the legislation and focuses on attitudes and potential behaviour change among adults and 
school-age children.(Doxey \& Hammond, 2011; Ford et al., 2013; Ford, MacKintosh, et al., 2013; Germain, Wakefield, \& Durkin, 2010; Shankleman et al., 2015; White \& Hammond, 2012) These studies suggest that standardised packaging reduces brand appeal and susceptibility to smoking, and increases attention to pack health warnings. Evidence of the impact the legislation on young adults in the UK, one in six of whom are smokers, is limited; student populations offer a convenient opportunity to investigate the responses of young adults to standardised packaging in a timely fashion.(ONS, 2016.)

This study investigated university students' awareness of and attitudes towards the legislation and sightings of the new packs 5-6 months into the implementation period, as well as their views on potential changes in smoking behaviour in response to the new legislation. We surveyed both smokers and non-smokers so as to compare awareness of attitudes towards the legislation between these groups.

\section{Methods}

\section{Design}

We conducted a cross-sectional survey of students at the University of Nottingham using the Bristol Online Survey (BOS) tool. Participants completed the survey between $26^{\text {th }}$ October and $26^{\text {th }}$ November 2016 . The study was approved by the University of Nottingham Faculty of Medicine and Health Sciences Research Ethics Committee.

\section{Study population and sampling method}

The study population was current University of Nottingham undergraduate and postgraduate students during the autumn term of the 2016-2017 academic year. Students studying outside the UK, such as those on years abroad, were excluded. Participants could be smokers or non-smokers. Smokers were defined as students who ever smoked, including "social smokers" who only smoke on rare social occasions.

To obtain a representative sample of students in the population a randomised cluster sampling method was used. We estimated that a sample of 423 would provide estimates of smoking prevalence to within $10 \%$. Given the relatively low response rate of previous similar studies, a large sampling frame was used.(Rutter, Britton, \& Langley, 2017) A random number generator was used to select four of the university's five faculties and three departments from each faculty. University courses from a list of all 93 offered by those 
departments were randomly selected. The administration at the University then forwarded an email from the researcher to all 3865 students studying the 32 selected courses. The email contained a short message inviting them to complete a survey about tobacco product packaging and a web link to the online survey. Participation was incentivised by optional entry into a prize draw to win a $£ 50$ Amazon voucher. Participation in the survey was anonymous, but those who wanted to be included in prize draw were required to provide their email address.

\section{Data Collection Instrument}

All respondents were asked about basic information including age, sex, whether they ever smoked, frequency of smoking, type of tobacco product and pack sized used, and whether they ever use e-cigarettes. We also asked questions about smoking among partipants' family and friends. Participants were then shown an image of a branded cigarette pack from one of the UK's top selling brands (Lambert and Butler Original, image provided by Action on Smoking and Health image library) and asked questions about whether they noticed the health warnings on the branded packs (yes/no/unsure), and whether they thought the health warning labels would put them off smoking (yes/no/unsure).(ASH, 2015.) Participants were then asked if they were aware of standardised packaging legislation prior to being given an explanation of the new legislation and being shown an image of a standardised cigarette pack meeting the specifications of those which have been introduced in the UK (image provided by Action on Smoking and Health image library). After viewing it they were asked if they had seen any standardised packs (yes/no/unsure), whether they noticed the health warnings on the packs (yes/no/unsure), and whether they thought the health warning labels would put them off smoking (yes/no/unsure), and whether they thought the change in packaging was a good idea (very good/fairly good/fairly bad/very bad/ unsure). Smokers were asked how willing they would be to pay current prices for a pack bearing this packaging (yes/no/unsure) and if they thought that they would make behaviour changes such as quitting or switching to a cheaper brand or alternative products as a result of the legislation.

The survey was piloted in a small student group prior to distribution. The questionnaire is available in supplementary online material.

\section{Statistical analysis}


The survey data were exported from the BOS server into Microsoft Excel and then imported into STATA version 14.0 for analysis. Descriptive analysis of the sample demographics was performed.

Univariate and multivariate logistic regression models were run to investigate if smoking status or any other factors influenced student awareness and acceptance of the new legislation. An additional model was run for smokers only, to investigate which factors influenced whether a student anticipated that they would quit in response to the legislation. Age and sex were included in all models as a priori variables. Other variables (smoking status, e-cigarette use, number of close friends who smoke and number of immediate family members who smoke) which it was hypothesised might influence legislation awareness and perceived acceptability were also tested in each model. Number of close friends who smoke was defined as the number of friends who ever smoke out of the ten friends who the respondent spent the most time with whilst at University. Immediate family members were defined as parents/siblings. All the variables were coded as binary variables except age and numbers of friends and family who smoke which were treated as continuous variables in the model. A variable was included in the multivariate model if it was statistically significant $(\mathrm{p}<0.05)$ in the univariate model.

\section{Results}

\section{Sample characteristics and smoking behaviour}

546 of the 3865 students contacted participated in the survey giving a response rate of $14.1 \% .58 \%$ of the sample was female and the median age was 19 (IQR 18-21) (Table 1).

$31.3 \%$ of students were smokers and $9.2 \%$ ever used e-cigarettes. $26 \%$ of smokers reported using e-cigarettes, compared with $1.3 \%$ of non-smokers.

Although the majority of smoking students smoked monthly or less than monthly, $26 \%$ of smokers in the sample reported being daily smokers. Equal proportions of students reported that they usually bought 10-14 cigarette packs and 20 cigarette packs; however a third reported not buying their own tobacco products.

\section{TABLE 1}

\section{Awareness of and responses to standardised packaging}


Over half of the sample was aware of the new legislation, but only $12 \%$ had seen a standardised pack (Table 2). Over $90 \%$ of the sample thought that the legislation was a very or fairly good idea, including over $80 \%$ of smokers. Frequent smokers were more likely than infrequent smokers to be aware of standardised packaging and to have seen a standard pack, but less likely to think it was a very good idea.

The majority of student smokers reported that their likely response to the legislation would be cutting down on smoking $(61 \%)$, quitting $(46 \%)$ or switching to cheaper brand (29\%) (Table 2, multiple responses permitted). One in five student smokers anticipated switching to e-cigarettes in response to the new legislation (Table 2).

In the logistic regression analyses being a smoker was still found to be associated with greater awareness of the new legislation $(\mathrm{OR}=2.15,95 \% \mathrm{CI}=1.41-3.27)$ (Table 3). No other factors were significantly associated with awareness of the new legislation. Smokers were still found to be significantly less likely to find the new legislation acceptable ( $O R=0.66$, $95 \% \mathrm{CI}=0.45-0.95)$.

Smokers who smoked less than once a month were over three times as likely to believe that they would quit in response to the new legislation than those who smoked daily $(\mathrm{OR}=3.30 \mathrm{CI}=1.06-10.00)($ Table 4$)$.

TABLE 2.

TABLE 3.

TABLE 4.

\section{Warning message effectiveness (data not shown)}

After being shown an image of both a branded and a standardised pack, all participants were asked about the health warnings on tobacco packaging. Both smokers and non-smokers were significantly more likely to report noticing the health warnings on the standardised packs $(\mathrm{p}<0.001)$ than on branded packs. 99\% of non-smokers reported noticing the warnings on standardised packs compared with $90 \%$ on the branded packs $(\mathrm{p}<0.001)$. $99 \%$ of smokers noticed the warnings on standardised packs, but only $79 \%$ notice them on the branded packs $(\mathrm{p}<0.001)$. Most non-smokers $(92 \%)$ also reported that the warnings on the standardised packs deterred them from starting smoking, as opposed to just under two thirds for the branded packs $(60 \%, \mathrm{p}<0.001)$. Well over half of smokers reported that the warnings 
on the standardised packs made them want to quit (59\%), compared with under a quarter for the branded packs $(23 \%, \mathrm{p}=0.048)$.

\section{Discussion}

This study found that in the autumn of 2016 only a small proportion of students had seen a standardised pack, suggesting that implementation of the new packaging was low 5-6 months into the 12 month transition period. Fewer smokers than non-smokers found the new legislation acceptable, but overall acceptability was high. Students reported that the warning messages on standardised packs are clearer and more effective at deterring both smokers and non-smokers. Many smokers anticipated that they would quit, cut down or switch to other products in response to the new legislation. One in five said they would switch to ecigarettes.

This study has a number of strengths and limitations. The timing of the study was advantageous in that it allowed awareness and acceptability to be studied during the transition between branded and standardised packaging. The online survey design ensured anonymity and therefore minimised the risk of social desirability bias.(Durkin et al., 2015; Gillham, 2008) While the response rate was relatively low, the sample size was high compared to prior studies of this type in this population.(Rutter et al., 2017) The study population is unlikely to be representative of young people in the UK and therefore cannot be generalised beyond student populations. However, the sample reflected that the majority of the university's students are aged between 18 and 20. The sample consisted predominantly of young adults and the survey therefore captured the views of a key target group for standardised packaging legislation. Furthermore, while 30\% of our sample reported ever smoking, only about one in five respondents smoked at least monthly. This is comparable to estimates of national smoking prevalence in this age group (17\% in 18-24 year olds in the UK in 2015) and suggests that our sample is representative in terms of smoking behaviour.(ONS, 2016.)

Our study is based on self-reported data and, given decreasing trends in smoking about young adults in the UK, there is a risk of reporting bias due to the decreasing acceptability of smoking.(ONS, 2016) However, responses to our study were anonymous, and this is therefore unlikely to have had a significant impact on our findings. A key 
limitation of the study is that our findings on potential behaviour change are hypothetical and may therefore not be borne out in practice. Consistent monitoring and evaluation will be required among all age groups to establish the impact of standardised packaging on smoking behaviour.

A high proportion of students were aware of the new packaging legislation; this is unlikely to have been influenced by the invitation to take part in the study, which did not mention the legislation. Despite high levels of awareness in the autumn of 2016, particularly among frequent smokers, very few students had actually seen one of the new standardised packs. This was true of both frequent and infrequent smokers. This suggests that implementation of the legislation was delayed as far as possible in the implementation period. It is possible the companies exploited the one year implementation period by flooding the market with a large stock of branded packs prior to the May deadline. This is supported by evidence from Australia where even shortly before the implementation deadline, only a limited proportion of tobacco products were being sold in standardised packaging: 2 months before the deadline less than $20 \%$ of packs being sold bore the new packaging, suggesting that tobacco companies apparently sought to delay the impact of standardised packaging legislation.(Scollo \& Lindorff, 2015) Given the small proportion of respondents that had seen a new pack, there is potential for novelty bias whereby the novel nature of the standardised packs makes students perceive them to be more effective.(Dunlop et al., 2014) However preliminary findings from Australia suggest that these perceptions will not diminish over time.(Wakefield et al., 2015)

The acceptability of the legislation was found to be very high, with a large proportion of respondents saying it was a good idea. This is consistent with evidence from the UK general population. In January 2015 support for the change to packaging was estimated at 72\%.(Cancer Research UK, 2015.) Evidence from Australia, where support increased after the implementation of the new legislation suggests that support for standardised packaging in the UK could continue to increase further now that the legislation has been fully implemented.(Swift et al., 2015; Young et al., 2014)

Students were more likely to notice the health warnings on the standardised packs; the literature suggests this is likely due to the removal of distracting imagery/branding. ${ }^{34}$ In line with this finding, more students reported being deterred by the health warnings on the standardised packs than those on the branded packs. This suggests that the new health 
warnings will be more effective at deterring young people from starting smoking and encouraging current young smokers to quit; however, it is unclear from this study whether this effect is due to the new, larger health warnings featured on the packs or due to changes in the overall pack design.

Nearly half of student smokers said they expected to quit in response to the legislation, although less frequent smokers were much more likely to say that they would do so than regular smokers. While these changes in behaviour may not be fully borne out in practice, it is encouraging that the new packaging is leading young adults to consider quitting. One in five smokers said they would switch to e-cigarettes which highlights the potential of these products as an alternative to tobacco in the context of standardised packaging implementation. Nevertheless, there was some inconsistency in students' responses, with $61 \%$ saying they would cut down, $41 \%$ that they would switch to handrolling tobacco and $29 \%$ saying they would switch to a cheaper brand. This indicates that many students are likely to engage in price minimising behaviours as opposed to quitting, thus undermining the effect of the new packaging. It underlines the need for measures to reduce the appeal of switching products, in particular reducing the price differentials between different products, if the effect of standardised packaging is to be maximised.

Six months into the 12 month transition period, the majority of students had not yet seen a standardised pack. However, the majority of students supported the new legislation, and our findings suggest that some young adults will attempt to quit or switch to e-cigarettes in response to the new legislation. Longitudinal research will be required to investigate whether these expected outcomes are borne out. 
Impact of standardised tobacco packs on students

\section{References}

Action on Smoking and Health. (2015). The UK tobacco industry. Retrieved from http://ash.org.uk/files/documents/ASH 123.pdf

Borland, R., Savvas, S., Sharkie, F., \& Moore, K. (2013). The impact of structural packaging design on young adult smokers' perceptions of tobacco products. Tobacco Control, 22, 97-102.

Cancer Research UK. (2015, January). Cancer Research UK welcomes Government action on standardised cig packs with voter support at a high of nearly three quarters. Retrieved from http://www.cancerresearchuk.org/about-us/cancer-news/press-release/2015-01-21-cancer-research-ukwelcomes-government-action-on-standardised-cig-packs-with-voter-support-at-a-high

Department of Health. (2016). Tobacco Packaging Guidance: Guidance for retailers and distributors of tobacco products, enforcement agencies and the public on changes to tobacco packaging. Retrieved from https://www.gov.uk/government/publications/packaging-of-tobacco-products Diethelm, P., \& Farley, T. (2015). Refuting tobacco-industry funded research: empirical data shows decline in smoking prevalence following introduction of plain packaging in Australia. Tobacco Prevention and Cessation, 1(6).

Directive 2014/40/EU of the European Parliament and the Council on the approximation of the laws, regulations and administrative provisions of the Member States concerning the manufacture, presentation and sale of tobacco and related products and repealing Directive 2001/37/EC, (2014). Doxey, J., \& Hammond, D. (2011). Deadly in pink: the impact of cigarette packaging among young women. Tobacco Control, 20(5), 353-360.

Dunlop, S., Dobbins, T., Young, J, Perez, D., \& Currow, D. (2014). Impact of Australia's introduction of tobacco plain packs on adult smokers' pack related perceptions and responses: results from a continuous tracking survey. BMJ Open, 4(12).

Durkin, S., Brennan, E., Coomber, K., Zacher, M., Scollo, M., \& Wakefield, M. (2015). Short-term changes in quitting-related cognitions and behaviours after the implementation of plain packaging with larger health warnings: findings from a national cohort study with Australian adult smokers. Tobacco Control, 24, 26-32.

Ford, A, Moodie, C., MacKintosh, A., \& Hastings, G. (2013). Adolescent perceptions of cigarette appearance. European Journal of Public Health, 24(3), 464-468.

Ford, A., MacKintosh, A., Moodie, C., Richardson, S., \& Hastings, G. (2013). Cigarette pack design and adolescent smoking susceptibility: a cross-sectional survey. BMJ Open, 3(9).

Ford, A., Moodie, C., Mackintosh, AM, \& Hastings, G. (2013). How adolescents perceive cigarette packaging and possible benefits of plain packaging. Education and Health, 31,83-88.

Gendall, P., Hoek, J., Thomson, G., Edwards, R., Pene, G., Gifford, H., Pirikahu, G., \& McCool, J. (2011). Young adults' interpretations of tobacco brands: implications for tobacco control. Nicotine and Tobacco Research, 13, 911-918.

Germain, D., Wakefield, M., \& Durkin, S. (2010). Adolescents' perceptions of cigarette brand image: does plain packaging make a difference? . Journal of Adolescent Health, 46(4), 385-392.

Gillham, B. (2008). Developing a Questionnaire (Second ed.). London: Bloomsbury.

Hammond, D., Dockrell, M., Arnott, D, Lee, A., \& McNeill. (2009). Cigarette pack design and perceptions of risk among UK adults and youth. European Journal of Public Health, 19(6), 631-637. Hammond, D., \& Parkinson, C. (2009). The impact of cigarette package design on perceptions of risk. Journal of Public Health, 31, 345-353.

Maynard, O., Munafo, M., \& Leonards, U. (2013). Visual Attention to Health Warnings on Plain Tobacco Packaging in Adolescent Smokers and Non-Smokers. Addiction, 108(2), 413-419.

Moodie, C., Angus, K., Stead, M., \& Bauld, L. (2013). Plain Tobacco Packaging Research: An update. Centre for Tobacco Control Research, University of Stirling. Retrieved from http://www.stir.ac.uk/media/schools/management/documents/Plain\%20Packaging\%20Studies\%20Up date.pdf

Moodie, C., Stead, M., Bauld, L., McNeill, A., Angus, A., Hinds, K., Kwan, I., Thomas, J., Hastings, G., \& O'Mara-Eves A. (2012). Plain Tobacco Packaging: A Systematic Review. Retrieved from http://phrc.lshtm.ac.uk/papers/PHRC_006_Final_Report.pdf 
Office for National StatisticsNS. (2016). Adult smoking habits in the UK: 2016. (Office for National Statistics Statistical Bulletin). Retrieved from

https://www.ons.gov.uk/peoplepopulationandcommunity/healthandsocialcare/healthandlifeexpectanci es/bulletins/adultsmokinghabitsingreatbritain/2016\#e-cigarette-use-in-great-britain-using-data-fromthe-opinions-and-lifestyle-survey-2014-to-2016-adults-aged-16-and-over

Rutter, L., Britton, J., \& Langley, T. (2017). Price-Minimizing Behaviors in Response to Increasing Tobacco Price: A Cross-Sectional Study of Students. Journal of Child and Adolescent Substance Abuse, 26(5), 367-375.

Scheffels, J., \& Saebo, G. (2013). Perceptions of Plain and Branded Cigarette Packaging Among Norwegian Youth and Adults: A Focus Group Study. Nicotine \& Tobacco Research, 15, 450-456.

Scollo, M., \& Lindorff, K. (2015). Standardised packaging and new enlarged graphic health warnings for tobacco products in Australia. Tobacco Control, 24(2), 9-16.

Shankleman, M., Sykes, C., Mandeville, K. L., Di Costa, S, \& Yarrow, K. (2015). Standardised (plain) cigarette packaging increases attention to both text-based and graphical health warnings: experimental evidence. Public Health, 129(1), 37-42.

Swift, E., Borland, R., Cummings, M., Fong, G., McNeill, A., Hammond, D., Thrasher, J., Partos, T., \& Yong, H.-H. (2015). Australian smokers' support for plain or standardised packs before and after implementation: findings from the ITC Four Country Survey. Tobacco Control, 24(6), 616-621. The Standardised Packaging of Tobacco Products Regulations 2015 No. 829, (2015). Wakefield, M., Coomber, K., Zacher, M., Durkin, S., Brennan, E., \& Scollo, M. (2015). Australian adult smokers' responses to plain packaging with larger graphic health warnings 1 year after implementation: results from a national cross-sectional tracking survey. Tobacco Control, 24, 17-25. White, C., \& Hammond, D. (2012). The potential impact of plain packaging of cigarette products among Brazilian young women: an experimental study. BMC Public Health, 12(737). Young, J., Stacey, I., Dobbins, T., Dunlop, S., Dessaix, A., \& Currow, D. (2014). Association between tobacco plain packaging and Quitline calls: a population-based, interrupted time-series analysis. The Medical Journal of Australia, 200(1), 29-32. 